\title{
Diálogo: conceito, princípios epistemológicos e implicações éticas
}

\author{
Rafael de Araujo Arosa Monteiro' \\ Renata Ferraz de Toledo² \\ Pedro Roberto Jacobi ${ }^{3}$
}

\section{Resumo}

Neste ensaio teórico, desenvolvido por meio de uma revisão narrativa da literatura, buscamos elaborar uma compreensão teórica a respeito do diálogo, entendido como um modelo participativo de interação, a partir das dimensões epistemológica e ética do ser humano. Com isso, enunciamos as noções de antidialogicidade e dialogicidade, cada qual caracterizada por uma forma particular de pensar, conversar, agir e aprender, como caminhos orientadores possíveis de nossas relações interpessoais.

Palavras-chave: Diálogo; Dialogicidade; Antidialogicidade.

\begin{abstract}
In this theoretical essay, developed through a narrative review of literature, we seek to elaborate a theoretical understanding about the dialogue, understood as a participatory model of interaction, from the epistemological and ethical dimensions of the human being. With this, we enunciate the notions of antidialogicity and dialogicity, each one characterized by a particular way of thinking, talking, acting and learning, as possible guiding paths of our interpersonal relationships.
\end{abstract}

Key words: Dialogue; Dialogicity; Antidialogicity.

\footnotetext{
' Doutorando e Mestre em Ciências pela Universidade de São Paulo (PROCAM - USP). Especialista em Educação Ambiental para a Sustentabilidade (Senac - São Paulo). rafael.araujo.monteiro@usp.br

2 Graduada em Ciências Biológicas (Modalidade Licenciatura) pela UNESP, campus de Botucatu-SP (1997); Especialista em Educação Ambiental pela Faculdade de Saúde Pública USP (1999); Mestre (2002) e Doutora (2006) em Saúde Pública pela Faculdade de Saúde Pública da USP. Possui Pós-doutorado pela Faculdade de Educação da USP

(2013). renata.toledo@saojudas.br

3 Possui graduação em Ciências Sociais (1973) e em Economia (1972) pela Universidade de São

Paulo. Mestrado em Planejamento Urbano e Regional pela Graduate School of Design -

Harvard University (1976), Doutorado em Sociologia pela Universidade de São Paulo (1986). Livre

Docente em Educação -USP. prjacobi@gmail.com
} 


\section{VOZES $_{\text {\&IÁLORO }}$}

Itajaí, V. 20, n.02, jun-dez 2021

\section{Introdução}

A noção de diálogo é bastante presente no senso comum. Uma alternativa possível para lidar com conflitos e evitar a violência. Apesar disso, sua definição não parece tão clara. É possível identificar a concepção de que se trata de uma conversa entre duas pessoas (alusão ao prefixo “di-"), de ser sinônimo de um debate "amigável” entre pessoas de posições divergentes, de ser um caminho para a busca de consensos, entre outras. No campo acadêmico também vigora uma diversidade de concepções, apesar de parecer haver alguns princípios compartilhados entre teóricos clássicos do assunto, como Martin Buber, David Bohm, Mikhail Bakhtin, Hans-Georg Gadamer e Paulo Freire.

O objetivo deste ensaio teórico é o de apresentar e desenvolver uma compreensão teórica a respeito do diálogo, entendido como um modelo participativo de interação, conceituando-o a partir de aspectos que se encontram na base da constituição humana de conhecer e se relacionar com o outro (seja ele humano ou não). Para isso, adotamos a revisão narrativa da literatura (CASARIN et al. 2020) como estratégia metodológica, por permitir a confrontação e costura das ideias de diferentes autores de forma mais livre, não sistematizada, para atender ao objetivo proposto.

Buscamos nos apropriar e, de alguma forma, atualizar as ideias do físico estadunidense, David Bohm, a respeito do funcionamento epistemológico do pensamento, desenvolvidas nos anos 90, agregando ideias de autores contemporâneos de diferentes áreas do saber - em particular da biologia, psicologia, neurociência, filosofia, sociologia e história da ciência. Além disso, buscamos associar a tal compreensão epistemológica uma perspectiva ética, no intuito de entender como tal epistemologia alimenta e é alimentada por um sistema de valores que orientam as ações humanas. Assim, desenvolvemos as noções de antidialogicidade e de dialogicidade enquanto formas de orientar a maneira pela qual conhecemos e nos relacionamos.

\section{Uma compreensão da constituição epistemológica e ética do ser humano}

\section{O que é e como funciona o pensamento?}

Para Bohm (2007) o pensamento é um grande sistema de reflexos composto por intelecto, memórias, emoções, sentimentos, reações físico-químicas do corpo e cultura. Esses componentes funcionam conjuntamente, retroalimentando-se. Para entender esse grande sistema é relevante compreender o significado de reflexo, o qual pode ser entendido como uma extensa cadeia automática de causa e efeito que une os diversos processos internos de nossos corpos (BOHM, 2007). O que Bohm (2007) está tratando aqui é do 


\section{VOZES $_{\& \text { DIÁLORO }}^{\mid}$}

Itajaí, V. 20, n.02, jun-dez 2021

funcionamento daquilo que Kahneman (2012) chamou de Sistema 1 do pensamento. De acordo com este autor, o pensamento se constitui por um caráter dual. Com o propósito de facilitar a compreensão de suas ideias, criou dois personagens fictícios: o Sistema 1 e o Sistema 2.

O Sistema 1 é rápido, intuitivo, automático, sem percepção de controle voluntário e exige pouco ou nenhum esforço. Algumas de suas funções estão ligadas à capacidades inatas, enquanto outras são aprendidas ao longo de nossas experiências, por meio de um processo conhecido como associação de ideias: causa e efeito (vírus-resfriado); objeto e sua propriedade (limão-verde); objeto e categoria à qual pertence (banana-fruta), a partir das quais constrói narrativas causais (KAHNEMAN, 2012).

Todo esse processo está diretamente ligado a uma série de capacidades biológicas inatas, responsáveis por garantir a manutenção de nossas vidas, caracterizando um processo conhecido como homeostasia. De acordo com Damásio (2004), esse processo atua por meio de diferentes componentes, os quais variam em nível de complexidade. Para o propósito deste ensaio, destacamos o papel e a relação entre os níveis mais alto em complexidade, as emoções e os sentimentos.

As emoções são uma forma natural, automática e inconsciente que nossos organismos dispõem para avaliar o ambiente que nos cerca e reagir de maneira adaptativa para a manutenção da vida (DAMÁSIO, 2004). Atrelados a elas estão os sentimentos, entendidos como "a expressão mental de todos os outros níveis da regulação homeostática" (DAMÁSIO, 2004, p. 32), possibilitando-nos "o controle voluntário daquilo que até então era automático" (DAMÁSIO, 2004, p. 63).

Kahneman (2012) esquematiza de maneira objetiva a interrelação entre uma ideia ou situação que nos afeta, a ativação associativa de nossa memória, a emergência de emoções, sentimentos e pensamentos correspondentes e as ações que materializamos como consequência:

A palavra [ou ideia] evoca lembranças, que evocam emoções, que por sua vez evocam expressões faciais e outras reações, tais como um aumento geral de tensão e uma tendência a evitar algo. A expressão facial e o gesto de evitar intensificam os sentimentos aos quais estão ligados, e os sentimentos por sua vez reforçam ideias compatíveis (p. 58, grifo nosso).

Cada elemento dessa rede associativa se reforça criando padrões de reações cognitivas, emocionais e físicas - os reflexos bohmianos, que nos auxiliam a interpretar e compreender determinada situação do presente e a estar preparados para lidar com contextos futuros parecidos, aumentando nossas chances de manutenção da vida (KAHNEMAN, 2012).

Essa capacidade interpretativa do presente com base no passado para antever o futuro, promovida pelos reflexos, alimenta a construção de crenças, ou seja, a expectativa da repetição de algo com base em experiências passadas, como sugeriu Hume (2004). Uma 


\section{VOZES $_{\text {\&IÁLORO }}^{\mid}$}

Itajaí, V. 20, n.02, jun-dez 2021

definição mais atual de crença é aquela proposta por Alcock (2018): as convicções (certezas) que temos a respeito de algo, ou seja, de algum conteúdo.

Para compreender o processo de formação das crenças se faz necessário considerar o segundo personagem do pensamento proposto por Kahneman (2012), o Sistema 2. Ele é lento, racional, deliberado, com percepção de controle voluntário e exige esforço e atenção. Ele é ativado quando determinada situação ou evento viola a narrativa causal construída pelo Sistema 1, ou seja, nossa compreensão sobre o mundo. Além disso, é responsável por nosso autocontrole, uma vez que monitora e controla as sugestões de pensamentos e ações advindas do Sistema 1, endossando e permitindo a expressão de parte deles e suprimindo ou alterando outros.

Tendo isso em vista, a construção de crenças se dá da seguinte maneira: por meio dos nossos sentidos (visão, audição, olfato, paladar e tato) temos a percepção daquilo que ocorre fora de nossos corpos. Somos afetados pelo mundo exterior de maneira que as reações corporais (emoções) levam o Sistema 1 a realizar as associações automáticas entre eventos, criando impressões e intuições que são sugeridas ao Sistema 2, as quais, se aceitas, passam a se constituir enquanto crenças aprendidas e registradas em nossa memória, guiando nossas ações (DAMÁSIO, 2004; KAHNEMAN, 2012; ALCOCK, 2018).

Portanto, as crenças têm a função de auxiliar a sobrevivência humana, ajudandonos a compreender o mundo por meio da construção de significados sobre o que nos acontece, a embasar nossa identidade (individual, social e política) e a guiar nossas ações (ALCOCK, 2018). Sendo assim, é possível afirmar que as crenças nos ajudam a ter segurança sobre como viver a vida e a saber quem somos. Por isso, quando alguém ou alguma situação desafia aquilo que acreditamos pode se instaurar o mal-estar, pois nossa sensação de segurança é abalada e nosso equilíbrio interno (homeostasia) desbalanceado.

Frente a tais situações, Alcock (2018) afirma que possuímos diversos mecanismos para a manutenção de nossas crenças e, portanto, de nosso bem-estar, os quais fomentam aquilo que Bohm (2005; 2007) chamou de noção de necessidade, ou seja, a crença de que algo é absolutamente necessário, contribuindo para a manutenção dos valores e princípios socialmente compartilhados a partir do tecido invisível da cultura, último elemento do sistema do pensamento bohmiano, que nos atravessa a todos e orienta nossas ações individuais e coletivas.

Ao tratar da maneira como nos relacionamos e da orientação de nossas ações, chegamos ao campo da ética, entendida por Maturana (2002) como a "preocupação com as consequências que nossas ações têm sobre o outro" (p. 72). A emergência da ética surge da necessidade de considerarmos os desejos e sentimentos do outro para enfrentar um ambiente cada vez mais complexo e desafiador para a manutenção de nossa existência enquanto espécie. Para isso, foi, e ainda é, necessário fomentar a aceitação mútua entre as pessoas, bem como a criação de regras, normas e instituições que funcionem como 


\section{VOZES $_{\text {\&IÁLORO }}^{\mid}$}

Itajaí, V. 20, n.02, jun-dez 2021

elementos reguladores da vida social em prol do bem-estar individual e coletivo (DAMÁSIO, 2004; MATURANA, 2002).

\section{O fluir entre os campos epistemológico e ético do ser humano}

Podemos, portanto, vislumbrar uma síntese caracterizada pelo movimento fluído entre os campos epistemológico e ético que estão dentro e entre cada um de nós, interconectados e interdependentes. Para desenvolver essa ideia, assumimos dez componentes em formato de ação (verbo) que integram o campo epistemológico, são eles: associar (sistema 1), emocionar, sentir, raciocinar (sistema 2), memorizar, crer, ouvir, falar, agir e culturalizar. Todos esses componentes de ação compõem o sistema epistemológico humano, numa perspectiva não fragmentaria de inspiração bohmiana.

Para exemplificar tal complexidade, adotamos um caminho de ordenamento, apenas como possibilidade. O ponto de partida é aquilo que nos acontece, que nos afeta. Ao interagir com o outro, seja ele uma planta, um animal, um mineral, um objeto construído ou um outro ser humano, temos nossos componentes epistemológicos estimulados. Ao ouvir sobre a destruição de uma floresta nosso cérebro envia diversos sinais para o corpo (emoções), resgatando da memória os reflexos, fruto de associações passadas, e crenças. Então, sentimos e raciocinamos sobre o que escutamos. Assim, podemos falar para outros o que ouvimos, sentimos e pensamos. Podemos agir, pensar e sentir juntos. Tudo isso faz com que as ideias, significados e crenças sejam compartilhados, formando e reforçando o culturalizar.

Parece-nos possível afirmar que nos componentes ouvir, falar, agir e culturalizar residem pontos de contato com o campo ético, pois neles se evidencia o espaço do entre, aquele em que se funda nossas relações. Reforça-se a ideia de que estamos contínua e permanentemente nos influenciando, afetando e sendo afetados pelos campos epistemológicos dos outros, compartilhando ideias, sentimentos, crenças etc.

Mas, esses dois campos que compõem a constituição humana podem assumir diferentes orientações. Para facilitar a exposição e explicação de tais orientações, dividiremos os dez componentes dos campos em quatro grandes conjuntos. Iniciamos pelo Pensamento, composto pelo associar, emocionar, sentir, raciocinar, memorizar e crer; seguido pela Conversa, composto pelo ouvir e falar; pela $A$ ção, no qual o elemento "agir" pode ser subdivido em expressões faciais, gestos e comportamentos; e por último por Aprendizagem, composto pelo culturalizar. Isto nos permite convergir para os conceitos de antidialogicidade e dialogicidade, entendidos enquanto formas de orientar o Pensamento, a Conversa, a Ação e a Aprendizagem. 


\section{Antidialogicidade: princípios epistemológicos e éticos}

A orientação do antidiálogo será designada como antidialogicidade, pois possui características bastante específicas sobre a forma de pensar, de comunicar, de agir e de aprender, as quais estão atreladas aos valores modernos: a fragmentação da realidade, a separação sujeito-objeto, o ideal de progresso, a dominação do outro, a invasão cultural, a busca incessante pelo lucro, a superprodução, o super consumo, o individualismo e a competição (HARARI, 2018; SANTOS, 2008). Vamos a cada uma delas.

\section{Pensamento antidialógico}

Trata-se de uma forma de pensar em que o associar e o raciocinar são fortemente dominados por suas próprias limitações, caindo em perigosas armadilhas epistemológicas ao buscar compreender a realidade. O limite do associar é o de assumir que "o que você vê é tudo que há”. Com isso, constrói as narrativas causais com as informações disponíveis, não importando muito a quantidade, nem a qualidade dessas informações, mas sim a coerência da história que consegue construir. Essa busca pela coerência fomenta o conforto cognitivo, sensação agradável de que algo que acreditamos é verdadeiro, e evita a dúvida que causa tensão e desconforto, levando-nos a sucumbir aos vieses cognitivos, como o viés de confirmação, a super confiança, os efeitos de enquadramento a negligência com dados estatísticos (KAHNEMAN, 2012; PEIRCE, 1877).

O raciocinar também possui vieses, como o de crença, em que aceitamos a conclusão de algum argumento por fazer sentido com base no passado; o raciocínio sequestrador, uma forma que se dá quando algo surpreendente acontece e se busca explicação em uma condição precedente; e o raciocínio entimemático, em que realizamos uma conclusão baseada em um pressuposto não declarado (entimema) (ALCOCK, 2018).

Portanto, o pensamento antidialógico é caracterizado por uma forma de pensar em que não reconhecemos nossos vieses, sendo por eles dominados. Fechamo-nos em nossas próprias convicções (crer), uma vez que acreditamos na ideia de uma verdade única e transcendente, como sugere Maturana (1988; 2002), percebendo-nos enquanto seus legítimos porta-vozes junto com aquelas pessoas que compartilham de nossas crenças.

Em consequência, há pouco espaço para questionamentos, frequentemente vistos como ataques dirigidos às nossas identidades e a "verdade em si". Aqui, portanto, o emocionar se caracteriza pela agressão (MATURANA, 1988; 2002), promovendo sentimentos (sentir) de medo, desconfiança e insegurança, por exemplo. Logo, é preciso fortalecer evidências que sustentem nossas posições para serem utilizadas numa disputa argumentativa. 


\section{VOZES $_{\text {\&IÁLORO }}^{\mid}$}

Itajaí, V. 20, n.02, jun-dez 2021

\section{Conversa antidialógica}

Nesta forma de conversa o que importa é reafirmar aquilo que se pensa, buscando clamar para si a razão máxima por meio de uma disputa argumentativa. Para tanto, ouvese para rebater o que é dito (ISAACS, 1999), movido pelo automatismo concordo-discordo (MARIOTTI, s/d); ouve-se realizando julgamentos; ouve-se pouco e interrompe-se muito. Em paralelo, fala-se generalizando, impondo o que se pensa como a verdade única a ser aceita, com muito pouco espaço para dúvida e questionamentos; fala-se sem se preocupar em confirmar o que se interpretou do que foi dito pelo outro, distorcendo suas ideias.

A isso, somam-se uma série de estratégias, sugeridas por Arthur Schopenhauer (2014), filósofo alemão do século XIX, de que se pode lançar mão para atingir a vitória: desestabilizar o oponente; não se importar em fugir do assunto se estivermos a ponto de perder a disputa; partir para o ataque pessoal; entre outros.

Tal forma de conversar com o outro promove o silenciamento das diferentes vozes, uma vez que se criam assimetrias de poder com a disputa, selecionando, de um lado, aqueles que vencem e garantem para si o monopólio discursivo e, de outro, aqueles que perdem e têm suas vozes suprimidas, passando a ser desconsiderados enquanto legítimos em sua humanidade.

\section{Ação antidialógica}

Tais formas de pensamento e conversa citadas levam a formas particulares de agir, impelindo-nos a atitudes de dominação do outro, em especial daquele que é diferente, visto como uma possível ameaça. Com a intensificação do apego às nossas crenças, associando a elas fortes emoções e sentimentos (agressão que leva ao medo, a desconfiança, a insegurança etc.), passamos a nutrir um processo de moralização no qual percebemos as pessoas que conosco concordam como boas e as que pensam diferente como más. A isso, soma-se um segundo processo, chamado de factualização, no qual buscamos justificar nossas escolhas morais preferidas, aquelas que sustentam a nossa "verdade", a partir dos vieses cognitivos com o propósito de travesti-los como fatos morais, ilusoriamente embasados pela razão, a serem aceitos por todos, como sugerem Ringel, Rodriguez e Ditto (2019).

Esses processos de moralização e factualização da vida transformam os diferentes grupos sociais em tribos inimigas. Os outros são reduzidos a uma característica negativa, de forma que todos as pessoas pertencentes àquele grupo externo se reduzem a elas (MCCOY; RAHMAN; SOMER, 2018). Roubamos-lhes sua diversidade subjetiva, reduzindo-os a um aspecto que ameaça nosso bem-estar, fomentando em nós a desconfiança, o medo e o ódio. Como consequência, não reconhecemos o outro em sua legitimidade humana, negando-lhe, no extremo, seu direito de existir, fomentando uma 


\section{VOZES $_{\& \text { DIÁLORO }}^{\mid}$}

Itajaí, V. 20, n.02, jun-dez 2021

competição promotora de violência, em que nos afastamos e combatemos o diferente por quaisquer meios necessários, como exclusão, dominação e/ou extermínio (guerra).

\section{Aprendizagem antidialógica}

Essas formas de pensar, de conversar e de agir, caracterizados pela antidialogicidade, são aprendidas por nós, por meio do culturalizar, ao longo de nossa vida nas diferentes situações e contextos em que participamos. Por exemplo, se aprendemos com nossos pais, amigos, ou qualquer pessoa de nosso círculo social que determinado “tipo” de pessoa (ou situação) é má, inferior, uma ameaça, ou qualquer coisa do tipo, constroem-se os preconceitos, crenças a respeito do outro, que orientam comportamentos de afastamento ou de luta. Tal processo de internalização das crenças factuais que recebemos da cultura em que estamos inseridos, acabam se constituindo enquanto verdades socialmente compartilhadas (RINGEL; RODRIGUEZ; DITTO, 2019), as quais fomentam uma ética da exclusão.

Para além das diversas experiências cotidianas, vale a pena ressaltar o papel da educação formal tradicional na aprendizagem dessa ética excludente, já que aprendemos a antidialogicidade por meio de uma forma particular de aprender, que Freire (1981) qualificou de antidialógica.

Aos que tiveram/têm a oportunidade de ir à escola, são anos de vivência em um modelo de relação baseado na desconsideração do aluno enquanto agente ativo do processo educador, portador de voz; na valorização de um conteúdo técnico fragmentado em detrimento de capacidades complexas; da competição por uma vaga nas universidades e, posteriormente, no mercado de trabalho; na adoção passiva dos valores culturais, sem muito espaço para questionamento, frequentemente visto como sinônimo de rebeldia ameaçadora.

Tais aspectos da aprendizagem antidialógica são alguns exemplos da maneira como socializamos e mantemos esta lógica como caminho orientador de nossas vidas, inconsciente ou conscientemente, acarretando sérias consequências no campo ético.

\section{Consequências da antidialogicidade}

Fruto da forma de pensar, conversar, agir e aprender supracitadas, emerge um cenário de incoerência, como sugere Bohm (1980; 2007). Geramos uma série de problemas, sem perceber que o fazemos. Tentamos resolvê-los com aquilo que parece ser nossos melhores recursos com a intenção de buscar o nosso bem-estar e prosperidade, individual e coletiva, e, no entanto, os problemas parecem se intensificar.

Reconhecer tal incoerência, é um primeiro passo para o enfrentamento das inúmeras crises deflagradas, que juntas configuram um cenário de crise civilizatória 


\section{VOZES $_{\text {\&IÁLORO }}^{\mid}$}

Itajaí, V. 20, n.02, jun-dez 2021

planetária. Ademais, esse reconhecimento pode fomentar um processo de transição paradigmática (KUHN, 1998), estimulando a emergência de novas formas de pensar e agir que busquem superar as antigas. A seguir apresentamos a dialogicidade como um caminho possível para tal transição.

\section{Dialogicidade: princípios epistemológicos e éticos}

Nesta seção compartilhamos impressões e ideias a respeito de como podemos orientar nossos campos epistemológico e ético a partir de princípios dialógicos. Apresentamos, assim como no item da antidialogicidade, as características particulares de uma forma de pensar, de comunicar, de agir e de aprender.

\section{Pensamento dialógico}

O pensamento dialógico é aquele que reconhece a existência dos limites e vieses do associar e do raciocinar, buscando continuamente não se deixar dominar por eles, colocando-os em evidência para desafiar as posturas fatalistas e herméticas, a partir do encontro com o outro.

Por isso, é uma forma de pensar que está em constante busca da criticidade. Esta diz respeito ao reconhecimento e compreensão dos acontecimentos históricos para a construção e manutenção do contexto cultural em que vivemos, como sugere Freire (1981), e ao reconhecimento e compreensão de nossa trajetória pessoal de vida dentro de tal contexto, como propõe Morin (2003).

Sendo assim, a criticidade fomenta o reconhecimento do caráter contingente da “verdade”, sempre se desdobrando para nós, como defende Bohm (1980), e, portanto, nos afastando do perigo de generalizar interpretações feitas a partir das experiências vividas por um indivíduo ou grupo particular, como predomina na antidialogicidade. Aqui, passamos a assumir as interpretações enquanto verdades próprias, como aquilo que faz sentido para si e não necessariamente para o outro, fomentando uma postura de humildade e aceitação das diferentes compreensões sobre a vida.

Em consequência disso, o pensamento dialógico está constantemente aberto para o inesperado, enfrentando o desconfortável estado de dúvida e incerteza ao invés de evitálo a qualquer custo. Aceita ideias aparentemente opostas, sem lançar sobre elas julgamentos para definir qual a correta e qual a errada, realizando questionamentos que estimulem olhar de novo para aquilo que se acredita saber, para aquilo que parece ser uma verdade para si e para outros que pensam de maneira semelhante. Ou seja, busca readmirar as crenças ao invés de reafirmá-las como faz o pensamento antidialógico.

A isso soma-se a curiosidade genuína, caracterizada pelo interesse em compreender o diferente, o qual passa a ser aceito em sua legitimidade. A tal aceitação do outro enquanto um ser legítimo, Maturana (1988; 2002) chama de amor, emoção que nos acompanha 


\section{VOZES $_{\& \text { DIÁLORO }}^{\mid}$}

Itajaí, V. 20, n.02, jun-dez 2021

desde o início de nossa caminhada evolutiva. Fruto de tal emoção se desdobram sentimentos (sentii) de segurança, confiança e solidariedade, por exemplo.

O pensamento dialógico é também uma forma de pensar que está em constante busca da coerência. Esta se caracteriza pela identificação da relação entre intenção-açãoresultados, como proposto por Bohm (2007). As intenções se constituem enquanto ideias, embasadas em emoções, que se materializam em ações, as quais produzem resultados. Estes se dividem em desejados e não desejados. Quando realizamos ações que produzem resultados desejados em relação às nossas intenções há coerência.

No entanto, frequentemente, nossas ações costumam trazer tanto resultados desejados, quanto não desejados. Estes últimos são, geralmente, difíceis de identificar. Quando o fazemos, costumamos não perceber nossa contribuição para sua emergência, atribuindo, habitualmente, a responsabilidade a terceiros. Tal cenário configura uma grande incoerência do pensamento, a de não reconhecer seus limites e responsabilidades.

O pensamento dialógico, portanto, é aquele que assume a criticidade e a coerência, enquanto aspectos indissociáveis que se retroalimentam, para reconhecer e enfrentar as inúmeras incoerências invisíveis que nos permeiam a todos, possibilitando a emergência daquilo que se encontra por revelar, implicado, como diria Bohm (1980). Para que possamos avançar nesse processo fluído e aberto ao novo, uma forma particular de conversar com o outro pode nos auxiliar.

\section{Conversa dialógica}

A conversa dialógica é aquela na qual "no que quer que seja que eu seja contrário ao outro, eu disse SIM à sua pessoa, aceitando-a como parceiro de uma conversação genuína” (BUBER, 2014, p. 154), falando aquilo que é verdadeiro dentro de mim e ouvindo aquilo que é verdadeiro dentro do outro.

O que se expressa e se ouve na conversa dialógica são os significados em torno de ideias, de sensações corporais, de sentimentos e de histórias, permitindo a quem fala e a quem ouve compreender juntos a cultura em que estão imersos, os valores e crenças que orientam a maneira de pensar e agir, possibilitando a emergência de novas ideias sobre as formas de viver a vida (BOHM, 2005; ISAACS, 1999; FREIRE, 1981).

Para isso, ouve-se para compreender o Outro, movido pela curiosidade, buscando entender as razões pelas quais ele/ela pensa e age da maneira que pensa e age; ouve-se evitando interrupções; ouve-se sem fazer julgamentos. Em paralelo, fala-se evitando generalizações, compartilhando o que se pensa enquanto uma verdade possível, com espaço para dúvida e questionamento; fala-se buscando confirmar com o Outro as interpretações que se depreendem do que é dito. 


\section{VOZES $_{\text {\&IÁLORO }}^{\mid}$}

Itajaí, V. 20, n.02, jun-dez 2021

\section{Ação dialógica}

Fruto da forma de pensar e conversar supracitadas emergem ações dialógicas, caracterizadas por uma série de princípios éticos que orientam nossa forma de nos relacionar com o outro. Em primeiro lugar, há o reconhecimento de que somos seres da relação, como sugere Buber (1979; 2014), ou seja, de que nos constituímos a partir do outro. Sou porque somos.

Tal princípio incita a aceitação do outro, não mais visto como um objeto que nos serve de alguma forma ou pela desumanização da pessoa que nos ameaça por ser diferente, mas como um outro ser, legítimo em sua completude. Assim, regata-se e reconhece-se a humanidade em cada pessoa, em especial naquelas que pensam e agem de forma diferente das nossas.

Como estamos nos defrontando constantemente com faces da verdade, e não com uma versão pronta e acabada, passamos a também nos reconhecer enquanto inacabados. Bohm (2007) propõe a substituição da noção de um ser identificado pela noção de um ser criativo. Um ser identificado é aquele que se define por algo que acredita, atrelando sua existência à necessidade de manter e defender crenças, mesmo sob evidência de equívoco (característico da antidialogicidade). Por outro lado, um ser criativo é aquele que está "constantemente se revelando por intermédio de [ou da relação com] cada pessoa, ou [com a] natureza, ou de várias outras maneiras (...)" (p. 148). Reconhece-se, assim, nossa incompletude (FREIRE, 2002), promovendo a vontade pelo encontro com o outro, aproximando-nos do diferente, para nos aprimorar constantemente.

\section{Aprendizagem dialógica}

Todos os princípios e características supramencionadas do pensamento, conversa e ação dialógica, se assumidos, poderão fomentar um processo de aprendizagem individual e coletiva. Nesse sentido, a aprendizagem dialógica se caracteriza pela colaboração entre as pessoas envolvidas no processo de conhecer a si, o outro e o mundo, horizontalizando as relações a partir da garantia de voz a todas as pessoas envolvidas no processo, direta ou indiretamente, acolhendo a diversidade de pensamentos, como sugeria Freire (1981).

Tal aprendizagem não se limita ao âmbito escolar, mas se refere a toda interação interpessoal e com o mundo que uma pessoa tem, a partir da qual vai construindo, por meio das conversas e ações, o pensamento sobre a vida que vive. Mas, diferente da aprendizagem antidialógica, já bem estruturada e consolidada nas culturas ocidentais, como promover processos de aprendizagem, por meio do culturalizar, que estimulem a vivência do pensamento, da conversa e das ações dialógicas?

De imediato afirmamos não haver uma resposta única e certa. Muitos são os caminhos possíveis. Aqui, ressaltamos e nos apropriamos daquele que vêm sendo trilhado por educadoras e educadores do campo da Educação para a Sustentabilidade e da 


\section{VOZES $_{\text {\&IÁLORO }}^{\mid}$}

Itajaí, V. 20, n.02, jun-dez 2021

Aprendizagem Social, que assumem implícita ou explicitamente o diálogo de base freiriana e/ou bohmiana como um princípio orientador e um objetivo a ser alcançado em seus processos educadores.

Nesse contexto, a sustentabilidade se constitui enquanto um tema gerador (FREIRE, 1981), a partir do qual se desdobram os diversos problemas complexos da contemporaneidade. Portanto, ao contrário do que se pode pensar, não se limita à sustentabilidade "ambiental”, exclusivamente ecológica, enquanto mais uma disciplina hermética, fechada em si mesma, mas como o ponto de partida dos processos educadores.

Estes intercalam momentos de reflexão, que possibilitam a compreensão da realidade, e ação, caracterizado por intervenções no contexto em que se vive para transformá-lo em direção daquilo que se almeja, utilizando para isso uma forma especial de aprendizagem transformadora - a aprendizagem social, em que se busca aprender junto para intervir junto (JACOBI, 2013; JACOBI; MONTEIRO; SOUZA, 2020; MONTEIRO; SORRENTINO; JACOBI, 2020).

Dessa forma, a aprendizagem dialógica pode ser definida, a partir dos referenciais citados anteriormente, enquanto um processo no qual a interação entre diversos atores (políticos, técnicos, sociedade civil organizada, movimentos sociais e cidadãos), portadores de diferentes crenças e interesses, possibilita a aprendizagem colaborativa que, por sua vez, promove mudanças cognitivas e relacionais, contribuindo para a compreensão entre as pessoas envolvidas no processo e estimulando acordos que levam à ações coletivas promotoras de transformações estruturais.

\section{Considerações finais}

Neste ensaio buscamos desenvolver uma compreensão teórica a respeito do diálogo, a partir das dimensões epistemológica e ética do ser humano. Para tanto, enunciamos as noções de antidialogicidade e dialogicidade, cada qual caracterizada por uma forma particular de pensar, conversar, agir e aprender, como caminhos orientadores possíveis de nossas vidas individuais e coletivas.

Sugerimos que a dialogicidade pode auxiliar na superação das diversas contradições promovidas pelo paradigma antidialógico vigente, fomentando um salto qualitativo na convivência interpessoal, a partir do estímulo à compreensão, à conexão e à colaboração para o enfrentamento dos diversos problemas complexos do nosso tempo. Entendemos que se constitui enquanto um caminho mais coerente na garantia pela sobrevivência humana e na busca por um estado de melhor qualidade de vida.

É evidente que como qualquer processo de aprendizagem, o caminho do diálogo apresenta importantes desafios para sua realização, que devem ser reconhecidos e enfrentados, mas ainda assim representam uma possibilidade que se apresenta a nós. Uma forma de viver a vida a ser escolhida. 


\section{VOZES $_{\text {\&IÁLORO }}^{\mid}$}

Itajaí, V. 20, n.02, jun-dez 2021

\section{Referências}

ALCOCK, J. Belief: what it means to believe and why our convictions are so compelling. Amherst, New York: Prometheus Books, 2018.

BOHM, D. A totalidade e a ordem implicada. São Paulo: Cultrix, 1980.

BOHM, D. Diálogo: comunicação e redes de convivência. São Paulo: Palas Athena, 2005.

BOHM, D. O pensamento como um sistema. São Paulo: Madras, 2007.

BUBER, M. Eu e Tu. 2ª ed. São Paulo: Cortez \& Moraes, 1979.

BUBER, M. Do diálogo e do dialógico. São Paulo: Perspectiva, 2014.

CASARIN, S. T.; PORTO, A. R.; GABATZ, R. I. B.; BONOW, C. A.; RIBEIRO, J. P. \& MOTA, M. S. Tipos de revisão de literatura: considerações das editoras do Journal of Nursing and Health. J. nurs. health. 10 (5), 2020.

DAMÁSIO, A. Em busca de Espinosa: prazer e dor na ciência dos sentimentos. São Paulo: Companhia das Letras, 2004.

FREIRE, P. Pedagogia do Oprimido. 10ª ed. Rio de Janeiro, Paz e Terra, 1981.

FREIRE, P. Pedagogia da Autonomia: saberes necessários à prática educativa. 25 ed. São Paulo: Paz e Terra, 2002.

HARARI, Y. N. Sapiens: uma breve história da humanidade. Tradução Janaína Marcoantonio. Porto Alegre, RS: L\&PM, 2018.

HUME, D. Investigações sobre o entendimento humano e sobre os princípios da moral. São Paulo: Editora UNESP, 2004.

ISAACS, W. Dialogue and the art of thinking together: a pioneering approach to communicating in business and in life. New York: Doubleday, 1999.

JACOBI, P. R. Aprendizagem social e a formação de professores em educação para a sustentabilidade socioambiental. Geologia USP, Publicação especial, São Paulo, 6: 5-10, 2013.

JACOBI, P. R.; MONTEIRO, R. A. A.; SOUSA, D. T. P. Caminhos para uma nova ética em tempos pós COVID-19: o desafio de ampliar diálogos e aprendizagem social. 


\section{VOZES $_{\text {\&IÁLORO }}^{\mid}$}

Itajaí, V. 20, n.02, jun-dez 2021

In: SOBRINHO, L. L. P.; CALGARO, C.; ROCHA, L. S. COVID-19: Direitos Humanos e Educação. Itajaí: UNIVALI, pp. 287-303, 2020.

KAHNEMAN, D. Rápido e Devagar: duas formas de pensar. Rio de Janeiro: Objetiva, 2012.

KUHN, T. S. A estrutura das revoluções científicas. 5. ed. São Paulo: Editora Perspectiva S.A, 1998.

MARIOTTI, H. O automatismo concordo-discordo e as armadilhas do reducionismo $\mathrm{s} / \mathrm{d}$. Disponível em: http://escoladedialogo.com.br/escoladedialogo/index.php/biblioteca/artigos/concdisc/ Acesso em: 15 dez. 2020.

MATURANA, H. Reality: the search for objectivity or the quest for a compelling argument. The Irish Journal of Psychology, 9(1): 25-82, 1988.

MATURANA, H. Emoções e linguagem na educação e na política. $3^{\text {a }}$ Reimpressão. Belo Horizonte: Editora UFMG, 2002.

MCCOY, J.; RAHMAN, T.; SOMER, M. Polarization and the Global Crisis of Democracy: Common Patterns, Dynamics, and Pernicious Consequences for Democratic Polities, American Behavioral Scientist, 62 (1), 16-42, 2018.

MCCOY, J.; SOMER, M. Toward a Theory of Pernicious Polarization and How It Harms Democracies: Comparative Evidence and Possible Remedies, The ANNALS of the American Academy of Political and Social Science, 681 (1), 234-271, 2019.

MONTEIRO, R. A. A.; SORRENTINO, M.; JACOBI, P. R. (Orgs.). Diálogo e Transição Educadora para Sociedades Sustentáveis. São Paulo: IEE-USP : Editora Na Raiz, 2020.

MORIN, E. A cabeça bem-feita: repensar a reforma, reformar o pensamento. Tradução Eloá Jacobina. $8^{\mathrm{a}}$ ed. Rio de Janeiro: Bertrand Brasil, 2003.

PEIRCE, C. S. A fixação da crença. Popular Science Monthly, v. 12, pp. 1-15, 1877.

RINGEL, M. M.; RODRIGUEZ, C. G.; DITTO, P. H. What is right is right: a three-part account of how ideology shapes factual belief. In: RUTJENS, B. T.; BRANDT, M.J. Belief systems and the perception of reality. London and New York: Routledge, 2019.

SANTOS, B. S. Um discurso sobre as ciências. $5^{\underline{a}}$ ed. São Paulo: Cortez, 2008.

SCHOPENHAUER, A. A arte de ter razão: 38 estratégias para vencer qualquer debate. São Paulo: Faro Editorial, 2014. 